\title{
Optical fibre-based methodology for screening the effect of probiotic bacteria on conjugated linoleic acid (CLA) in curdled milk
}

\author{
Lurdes I.B. Silva $^{\mathrm{a}, \mathrm{b}, *}$, Dina M. Rodrigues ${ }^{\mathrm{b}}$, Ana C. Freitas ${ }^{\mathrm{b}}$, Ana M. Gomes ${ }^{c}$, Teresa A.P. Rocha-Santos ${ }^{\mathrm{a}, \mathrm{b}}$, \\ M.E. Pereira ${ }^{a}$, A.C. Duarte ${ }^{a}$ \\ ${ }^{a}$ CESAM E Department of Chemistry, University of Aveiro, 3810-193 Aveiro, Portugal \\ ${ }^{\mathrm{b}}$ ISEIT/Viseu, Instituto Piaget, Estrada do Alto do Gaio, Galifonge, 3515-776 Lordosa, Viseu, Portugal \\ ${ }^{\mathrm{c}}$ CBQF/Escola Superior de Biotecnologia, Universidade Católica Portuguesa, Rua Dr. António Bernardino de Almeida, 4200-072 Porto, Portugal
}

Keywords:

Optical fibre

GC-MS

Probiotic bacteria

CLA

Curdled milk

\begin{abstract}
A B S T R A C T
A methodology based on optical fibre (OF) detection was developed for screening the potential of CLA production by Lactobacillus casei-01, Lactobacillus acidophilus La-5 and Bifidobacterium lactis B94 in probiotic curdled milk. The OF based methodology was validated by comparison with an analytical method based on gas chromatography-mass spectrometry (GC-MS) and it showed comparable linearity (between 5 and $130 \mu \mathrm{g}$ ), accuracy and detection limits, which ranged from 1.92 to $2.56 \mu \mathrm{g}$ for CLA methyl ester and oleic acid methyl ester, respectively. Furthermore, the proposed OF based methodology was an advantageous analytical methodology for screening CLA production in probiotic curled milk, due to its compact design and effective cost of analysis.

The application of the OF analytical method allowed to detect CLA in the probiotic curdled milk; the production of CLA by probiotic enzymes reached values of $297 \pm 19 \mu \mathrm{g} \mathrm{g}^{-1}$ by 60 days of ripening unfolding this potential functional food as very interesting from a technological point of view.
\end{abstract}

\section{Introduction}

The term conjugated linoleic acid (CLA) refers to a group of polyunsaturated fatty acids that exists as positional and geometric conjugated isomers of linoleic acid (LA, cis-9:cis-12-18:2n-6). These isomers have been found to have several beneficial physiological effects, demonstrated in animal models and cell cultures derived from humans/animals. CLA has been reported to have anticarcinogenic, antiadipogenic, antiatherogenic, antidiabetogenic, immunomodulative and anti-inflammatory properties (Belury, 2002; Bhattacharya, Banu, Rahman, Causey, \& Fernandes, 2006; Kelley, Hubbard, \& Erickson, 2007; Wahle, Heys, \& Rotondo, 2004). According to Ritzenthaler et al. (2001), an intake of cis9:trans-11 intake must be 620 and $441 \mathrm{mg} / \mathrm{d}$ for men and women, respectively, to exhibit a cancer protective effect. Due to its potential health benefits, several CLA dietary supplements are currently commercialised, yet CLA occurs naturally in a variety of foods, especially in those derived from ruminant animals (Adamczak, Bornscheuer, \& Bednarski, 2008; Fritsche et al., 1999). Dairy products are the most important source of CLA in the diet where cis9:trans-11 isomer $((9 \mathrm{Z}, 11 \mathrm{E})$-octadeca-9,11-dienoic acid $)$ is the

* Corresponding author at: ISEIT/Viseu, Instituto Piaget, Estrada do Alto do Gaio, Galifonge, 3515-776 Lordosa, Viseu, Portugal. Tel.: +351 232910 100; fax: +351 232 910183.

E-mail address: lisilva@ua.pt (L.I.B. Silva). principal form of CLA; its concentration depends on animal's diet, breed and age (Bisig, Eberhard, Collomb, \& Rehberger, 2007).

Several microorganisms are able to synthesise CLA and therefore microbial conversion of LA to CLA by probiotic bacteria is desirable and adapts perfectly to the added-value of functional foods, a key research and innovation area in agro-research. Probiotics are viable microorganisms that can bring about health benefits to the host when administered in adequate amounts (Sanders, 2003). Lactobacillus and Bifidobacterium are among the common probiotic strains used in functional dairy products (Oliveira, Perego, Converti, \& de Oliveira, 2009) and their ability to synthesise free CLA in cultured dairy products brings about additional health and nutritional benefits; studies focusing on CLA production in fermentation of milk by Lactobacillus and Bifidobacterium strains have shown this potential (Coakley et al., 2003; Lin, Lin, \& Lee, 1999).

Due to the role of fatty acids in dairy products, fast and reliable methods for analysing CLA and other fatty acids are always desirable. Gas chromatography (GC) coupled to either a flame ionization detector (FID) or to a mass spectrometry detector (MS) are the most widely used methods for quantification of CLA (RodríguezAlcalá, Braga, Malcata, Gomes, \& Fontecha, 2011).

The main objective of this research was to develop, validate, and apply a methodology based on optical fibre detection for screening the potential of CLA production by Lactobacillus casei-01, Lactobacillus acidophilus La-5 or Bifidobacterium lactis B94 in probiotic curdled milk matrices. To accomplish the objectives, three fatty acids 
were screened: oleic acid, LA and CLA (as the (9Z,11E)-octadeca9,11-dienoic acid).

\section{Experimental}

\subsection{Probiotic curdled milk}

Probiotic curdled milk inoculated with either L. casei-01 (Chr. Hansen, Hørsholm, Denmark), L. acidophilus La-5 (Chr. Hansen, Hørsholm, Denmark) or B. lactis B94 (DSM) were produced according to Rodrigues et al. (2011). For each probiotic bacterium, $50-\mathrm{mL}$ portions of cow milk previously sterilized (at $110-112^{\circ} \mathrm{C}$ for $10 \mathrm{~min}$ ) were prepared and divided into two groups, to obtain control and probiotic curdled matrices. For the control group and per litter of milk it was added $6 \mathrm{~mL}$ of three times diluted animal rennet $(1: 15,000)$ (Naturen ${ }^{\circledR}$, from Chr. Hansen, Hørsholm, Denmark), $6 \mathrm{~mL}$ of $\mathrm{CaCl}_{2}$ (Panreac, Barcelona, Spain), and $10 \mathrm{~g}$ of $\mathrm{NaCl}$ (Panreac, Barcelona, Spain). Probiotic curdled milk shared the same composition, but were inoculated at $2 \%$ with $L$. casei-01, L. acidophilus La-5 or B. lactis B94, respectively. Milk coagulation was performed at $30^{\circ} \mathrm{C}$ for $5 \mathrm{~h}$. Upon coagulation, duplicates of each curdled milk matrix type were withdrawn and labelled as $0 \mathrm{~d}$. The remaining samples were incubated at $12{ }^{\circ} \mathrm{C}$ throughout 60 days of ripening period; duplicate samples were withdrawn at $15,30,45$ and 60 days.

\subsection{Microbiological analyses}

Viable cells of probiotic bacteria were obtained through $100 \mu \mathrm{L}$ aliquots plated, in duplicate in MRS agar (Biokar Diagnostics, Beauvais, France) containing $0.5 \mathrm{~g} / \mathrm{L}$ of $\mathrm{L}$-cysteine- $\mathrm{HCl}$ (Panreac, Barcelona, Spain) after sequential dilutions which were made with sterile $0.1 \%(\mathrm{w} / \mathrm{v})$ peptone water (Himedia, Mumbai, India) of curdled matrix homogenates (Rodrigues et al., 2011). Plating was followed by incubation at $37^{\circ} \mathrm{C}$ for $48 \mathrm{~h}$, under aerobic conditions for L. casei-01, and under anaerobic conditions for L. acidophilus La-5 and B. lactis B94. In order to check for contamination, microbiological counts were performed on plate count agar (Biokar Diagnostics, Beauvais, France) incubated aerobically at $37^{\circ} \mathrm{C}$ for $48 \mathrm{~h}$. No contamination was found over ripening period.

\subsection{Chemical analyses}

\subsubsection{Extraction}

Duplicated samples of each curdled milk (control or probiotic), were assessed for free fatty (FFA) acids and conjugated linoleic acids according to Alonso, Cuesta, and Gilliland (2003) with some modifications and Rodrigues et al. (2011) shacked vigorously. The mixture (sample and 2-propanol) was added to hexane ( $9 \mathrm{~mL}$ ). The sample $(6 \mathrm{~mL}$ ) was added to $12 \mathrm{~mL}$ of 2-propanol (Fluka, Sintra, Portugal and Panreac, Barcelona, Spain) shacked for an extra $3 \mathrm{~min}$ and placed in an ultra-sound bath (Ultrasonik, Montreal, Canada) for $30 \mathrm{~min}$. After settling, the upper layer was collected by aspiration and filtered with sodium sulphate anhydrous (Panreac, Barcelona, Spain). The sodium sulphate bed was washed with an additional $7 \mathrm{~mL}$ of hexane (added to the filtered mixture). The lipid fraction was collected in a $100 \mathrm{~mL}$ pear-shaped flask, and placed in a Rotavapor (Laborota 4000, from Heidolph, Schwabach, Germany) at $40{ }^{\circ} \mathrm{C}$ until dryness. The extract was redissolved in $500 \mu \mathrm{L}$ of hexane, and transferred to a microtube. A methanolic solution $(100 \mu \mathrm{L})$ was added to the tube containing the lipid fraction. The mixture was vortexed for $1 \mathrm{~min}$, and held at $7{ }^{\circ} \mathrm{C}$ for $15 \mathrm{~min}$ in a sandy bath. Methylation was carried out with $200 \mu \mathrm{L}$ of $14 \%(w / v)$ boron trifluoride in methanol (Sigma, Sintra, Portugal), at room temperature for $30 \mathrm{~min}$ and adding $0.2 \mathrm{~mL}$ of hexane to the mixture. Extracts were stored at $-20^{\circ} \mathrm{C}$ until analysis. Oleic acid, linoleic acid and CLA were analysed as methyl esters by the developed optical fibre-based methodology after its validation.

\subsubsection{GC-MS based methodology}

GC-MS based methodology was (Rodrigues et al., 2011) used in order to test and compare the performance of the OF methodology. Standards of each fatty acid methyl ester for calibration or ten standard mixtures with different concentrations of each fatty acid methyl ester were injected $(1 \mu \mathrm{L})$ in splitless mode, at $250^{\circ} \mathrm{C}$ on a GC-MS (QP5000, Shimadzu, IZASA, Lisbon, Portugal) operated in SIM mode. The fatty acids chromatography took place in a DB5 capillary column $(0.25 \mu \mathrm{m}$ film $\times 0.25 \mathrm{~mm} \times 30 \mathrm{~m})$ (Sigma, Sintra, Portugal) using Helium as carrier gas (linear velocity of $35 \mathrm{~cm} / \mathrm{s}$ ). The temperature program started at $80^{\circ} \mathrm{C}$, and increased until $300{ }^{\circ} \mathrm{C}$ at a rate of $8^{\circ} \mathrm{C} / \mathrm{min}$. The interface and MS detector temperatures were kept at $290^{\circ} \mathrm{C}$.

\subsection{Optical fibre-based methodology}

Fig. 1a shows the analytical apparatus of the optical fibre-based methodology (OF methodology) where the temperature of the injection cell (I) was controlled by a coiled tape heater from Cole Parmer, Montreal, Canada and a temperature sensor. The chromatographic column (C) contains a fused silica fibre coated with a film of phenyl methylpolysiloxane and was surrounded by another tape heater and a temperature sensor. The chromatographic column was connected to the flowmeter $(F)$, which kept a constant flow of nitrogen, and to the analytical tube (AT). The AT design includes an internal narrowed region of $0.4 \mathrm{~cm}$ of diameter and $6.5 \mathrm{~cm}$ long. Inside the analytical tube was the optical fibre $(0)$, which was previously uncladded and cleaved, with a Cleaver V6 (Future Instrument, Barcelona, Spain) precision fibre cleaver, to $15 \mathrm{~mm}$ of the optical path cord. In the cleaved fibre section a PDMS matrix was deposited resulting in the sensitive component of the OF methodology. The PDMS coating was deposited by dip-coating technique, dipping the optical fibre cleaved section into the PDMS solution. Besides optical fibre and the analytical tube the detection component of the OF methodology is also constituted by an laser diode optical source (L) with the working wavelength set at $1550 \mathrm{~nm}$ to generate the interrogating signal and a photodiode detector $(\mathrm{P})$ to measure the intensity of the modulated signal which was connected to the optical coupler (OC). The optical component $(\mathrm{O})$ of the detector is constituted by a monomode optical fibre pigtail, core and cladding diameters of 9 and $125 \mu \mathrm{m}$, respectively, integrated into a directional 50:50 Y optical coupler (OC). The optical coupler was also connected to the photodiode detector (P) which was connected to a laptop (PC) with homemade software.

Either individual standards of linoleic acid methyl ester, linoleic acid conjugated methyl ester and oleic acid methyl ester (Sigma, Sintra, Portugal), or ten different concentrations of standard mixtures, and samples ( $1 \mu \mathrm{L})$ were introduced by a gastight micro-syringe (Hamilton, Bonaduz, GR, Switzerland) at the top of the injector (I) kept at $290{ }^{\circ} \mathrm{C}$. After separation on the column at $290{ }^{\circ} \mathrm{C}$ the analytes reached the analytical tube which contains the coated optical fibre (O) generating an analytical signal (Fig. 1b). The changes in the reflected optical power caused by variations in the refractive index of optical fibre have been previously discussed by Silva, Rocha-Santos, and Duarte (2008a, 2008b, 2008c, 2008d, 2009) and Silva, M-Costa, Freitas, Rocha-Santos, and Duarte (2009), and depend on both coating film (PDMS) and analytes (oleic acid methyl ester, linoleic acid methyl ester and CLA methyl ester) properties, as well as the chemical interactions which can take place between these two elements. The different sensitivities (Fig. 1b) obtained for the three compounds tested can be attributed 


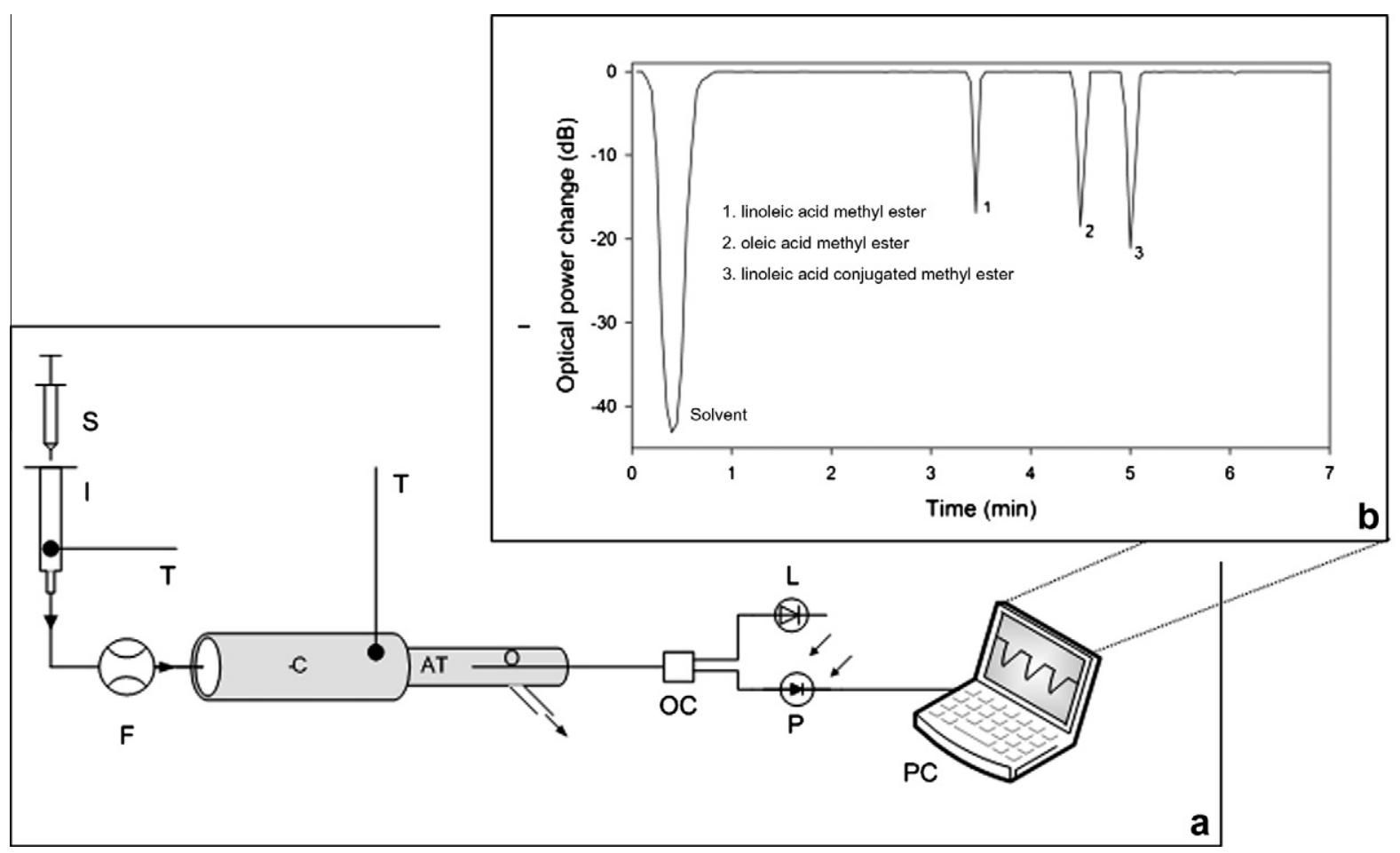

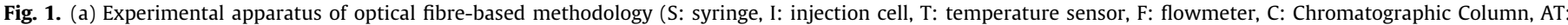

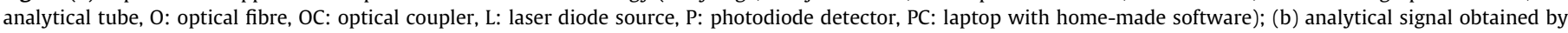
optical fibre-based methodology for a standard mixture $40.00 \mu \mathrm{g}$ of oleic acid methyl ester, linoleic acid methyl ester and linoleic acid conjugated methyl ester.

to the different analyte properties, such as the boiling temperature, the molecular weight and the vapour pressure. In this case the sensitivity varies in the same way as the boiling temperature (linoleic acid methyl ester <oleic acid methyl ester <CLA methyl ester).

\subsection{Quality assurance and quality control ( $Q A / Q C)$}

In order to assure representativeness and reliability of the results obtained, QA/QC procedures included blanks, duplicates and recovery assays. Replicate analysis of the curdled milk samples gave an uncertainty of $<5 \%$ for the three fatty acids (oleic acid, linoleic acid and CLA). Recovery assays were carried out to ensure effectiveness of the extraction procedure of the three fatty acids from curdled milk samples and recoveries ranged from 95 to $101 \%$. The calibration curves for both OF and GC-MS methodologies were obtained for five repeated measurements of five standard solutions containing a mixture of linoleic acid methyl ester, oleic acid methyl ester and CLA methyl ester in concentrations of 5.00, $10.00,40.00,70.00,100.00$ and $130.00 \mu \mathrm{g}$. The concentration of each compound was determined by direct interpolation in the standard curve within their linear dynamic range, and the detection limits were calculated using $y=y_{\mathrm{B}}+3 s_{\mathrm{B}}$, where $s_{\mathrm{B}}$ is the standard deviation (SD) of the blank signal estimated as $s_{\mathrm{y} / \mathrm{x}}$, the residual SD taken from the calibration line and $y_{\mathrm{B}}$ is the blank signal estimated from the intercept taken also from the calibration line (Miller \& Miller, 2005).

Ten different concentrations of standard mixtures $(10.00,30.00$ $40.00,50.00,70.00,80.00,90.00,100.00,110.00,120.00 \mu \mathrm{g}$ ) of each fatty acid methyl ester (linoleic acid methyl ester, oleic acid methyl ester and CLA methyl ester) were also obtained for five repeated measurements by both GC-MS and OF methodologies.

\subsection{Statistical methods}

All statistical analyses were performed using SigmaStat ${ }^{\mathrm{TM}} 3.0$ (SigmaStat, 1994).

A two way repeated measures analysis of variance (ANOVA) and all pairwise multiple comparison procedures performed by HolmSidak method, were applied to the results obtained for the ten standard mixtures analysed by the GC-MS and the OF methodologies together with the expected value for each standard mixture.

Table 1

Analytical parameters obtained for linoleic acid methyl ester, oleic acid methyl ester and CLA methyl ester with GC-MS and OF based methodologies.

\begin{tabular}{|c|c|c|c|c|}
\hline & Methodology & Linoleic acid methyl ester & Oleic acid methyl ester & CLA methyl ester \\
\hline \multirow[t]{2}{*}{ Retention time (s) } & GC-MS & 42.78 & 43.26 & 44.51 \\
\hline & OF & 3.52 & 4.27 & 5.05 \\
\hline \multirow[t]{2}{*}{ Linear range $(\mu \mathrm{g})$} & GC-MS & $5-130$ & $5-130$ & $5-130$ \\
\hline & OF & $5-130$ & $5-130$ & $5-130$ \\
\hline \multirow[t]{2}{*}{ Linear calibration } & GC-MS & $y=0.835 x+36.82$ & $y=0.835 x+40.59$ & $y=0.839 x+43.36$ \\
\hline & $\mathrm{OF}$ & $y=0.108 x+12.56$ & $y=0.109 x+13.99$ & $y=0.135 x+15.53$ \\
\hline \multirow[t]{2}{*}{ Squared coefficient of correlation $\left(\mathrm{R}^{2}\right)$} & GC-MS & $0.9997\left(p<3.22 \times 10^{-8}\right)$ & $0.9994\left(p<2.52 \times 10^{-6}\right)$ & $0.9998\left(p<2.08 \times 10^{-8}\right)$ \\
\hline & OF & $0.9997\left(p<3.39 \times 10^{-8}\right)$ & $0.9995\left(p<1.02 \times 10^{-7}\right)$ & $0.9997\left(p<3.21 \times 10^{-8}\right)$ \\
\hline \multirow[t]{2}{*}{ Detection limit $(\mu \mathrm{g})$} & GC-MS & 1.92 & 2.57 & 1.72 \\
\hline & OF & 1.94 & 2.56 & 1.92 \\
\hline
\end{tabular}




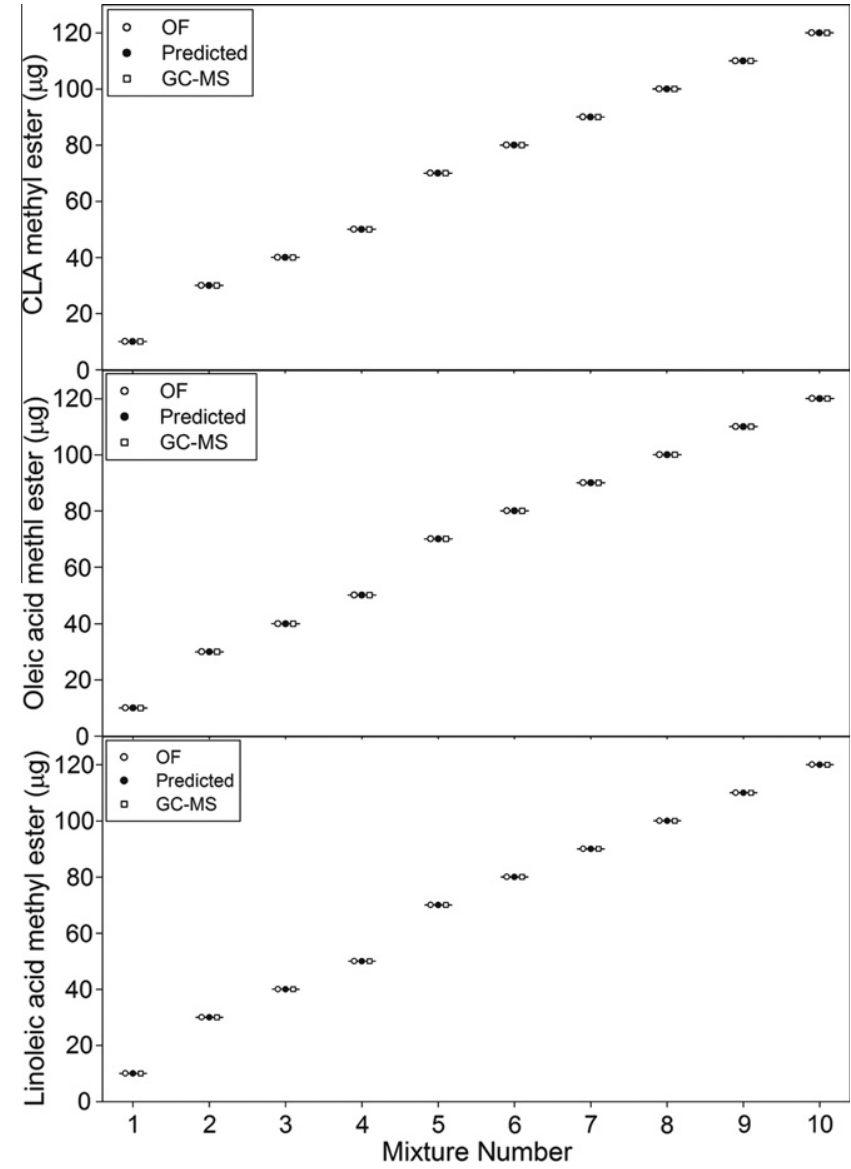

Fig. 2. Comparison of the results obtained with the OF and CG-MS methods for CLA methyl ester, oleic acid methyl ester, and linoleic acid methyl ester.

For control curdled milk as well as for each probiotic curdled milk, a one-way analysis of variance (ANOVA) was performed to analyse if the variation of oleic acid, linoleic acid, CLA and of viable cells of probiotic strain was significant throughout time at the 0.05 level of significance.

\section{Results and discussion}

The analytical time for the OF methodology (Fig. 1b) was 7 min against 46 min obtained for GC-MS due to different instrumentation and operational conditions of the analytical system, namely different chromatographic components, different temperature programs and different carrier gas flow rates. The retention times and other analytical parameters can be observed in Table 1 . The detection limits, in $\mu \mathrm{g}$, were in a range from 1.72 to 2.57 , and from 1.92 to 2.56, for the GC-MS and OF methodologies, respectively. The linear range was $5-130 \mu \mathrm{g}$ for both methodologies.
At a 95\% confidence level, the response of the OF methodology shows calibration sensitivities, measured as the slope of the calibration curve, which increases in the following order: linoleic acid methyl ester < oleic acid methyl ester <CLA methyl ester. The different sensitivity obtained for the three compounds tested was already discussed in the Section 2 and can be attributed to different analyte properties, such as the boiling temperature.

Fig. 2 shows the results (predicted value and obtained by OF and GC-MS methodologies) from the ten standard mixtures with different concentrations used to evaluate the performance of OF methodology. The ANOVA of these results allowed to concluded that there are no significant differences between the results obtained by the two methods ( $p=0.848,0.706,0.203)$ for linoleic acid methyl ester, oleic acid methyl ester and CLA methyl ester, respectively). Although there is a statistical significance $(p<$ 0.001 ) for the effects of different levels of the expected value, the results obtained by the two methods do not depend on what level the expected value is present for linoleic acid methyl ester ( $p=$ $0.962)$, oleic acid methyl ester $(p=0.819)$ and CLA methyl ester $(p=0.992)$.

The analytical error, measured as the residual standard deviation of both methods, was around $3 \times 10^{-2} \mu \mathrm{g}$.

The OF methodology after preliminary tests, comparison and validation against GC-MS methodology, was applied to the analysis of oleic acid, linoleic acid (LA) and CLA on curdled milk matrices inoculated with either probiotic strain (L. casei-01, L. acidophilus La-5 or B. lactis B94) and ripened through a period of $60 \mathrm{~d}$.

Probiotics are defined as live microorganisms which, when administered in adequate amounts, confer a health benefit on the host (FAO/WHO. Working Group Report on Drafting Guidelines for the Evaluation of Probiotics in Food. London, Canada, \& May 1, 2002; Sanders, 2003) and therefore the viability and metabolic activity of these microorganisms are key factors that must be controlled during processing operations and maturation period. A statistical significant increase of viable cells $(p<0.05)$ for both B. lactis B94 and $L$. casei-01 was observed in the first 30 days of ripening followed by a decrease until 60 days (Table 2 ). In turn, the number of viable cells of $L$. acidophilus La-5 remained approximately constant through all ripening period; the variation of viable cells of $L$. acidophilus La-5 trough ripening time was not statistical significant $(p>0.05)$. Despite the different oscillations in viable cells observed for the three probiotic strains, the levels of each probiotic bacterium in curdled milk were around $10^{8} \mathrm{cfu} / \mathrm{g}$ through the 60 days of ripening. Although it is still not possible to accurately generalise a minimum dose of probiotics that is needed for a beneficial effect in the gut, some studies revealed positive effects at levels of $10^{8} \mathrm{cfu}$ per day (Douglas \& Sanders, 2008). Based on these guidelines, curdled milk revealed to be adequate food products to deliver probiotic concentrations capable of providing potential health.

No statistical significant variations of oleic or LA acid were observed through ripening period in the control curdled milk $(p>$ $0.05)$; CLA concentrations found in those samples were below detection limit (Table 2).

Table 2

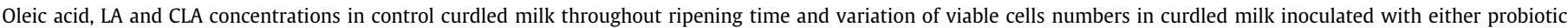
strain.

\begin{tabular}{|c|c|c|c|c|c|c|}
\hline \multirow{2}{*}{ Ripening time (d) } & \multicolumn{3}{|l|}{ Control curdled milk $(\mu \mathrm{g} / \mathrm{g})^{\mathrm{a}}$} & \multicolumn{3}{|l|}{ Probiotic curdled milk (log cfu/g) } \\
\hline & Oleic acid & LA & CLA & B. lactis B94 & L. casei-01 & L. acidophilus La-5 \\
\hline 0 & $823.4 \pm 3.0$ & $87.68 \pm 1.24$ & $<1.92$ & $8.1 \pm 0.2$ & $8.11 \pm 0.05$ & $8.26 \pm 0.08$ \\
\hline 15 & $823.9 \pm 1.7$ & $87.60 \pm 0.95$ & $<1.92$ & $9.6 \pm 0.1$ & $9.52 \pm 0.01$ & $8.3 \pm 0.2$ \\
\hline 30 & $824.2 \pm 2.5$ & $87.67 \pm 1.14$ & $<1.92$ & $9.525 \pm 0.009$ & $9.5 \pm 0.1$ & $8.2 \pm 0.2$ \\
\hline 45 & $826.2 \pm 0.4$ & $87.76 \pm 1.03$ & $<1.92$ & $8.8 \pm 0.3$ & $9.14 \pm 0.02$ & $8.5 \pm 0.1$ \\
\hline 60 & $823.2 \pm 0.9$ & $87.42 \pm 0.96$ & $<1.92$ & $7.66 \pm 0.04$ & $8.3 \pm 0.2$ & $8.52 \pm 0.01$ \\
\hline
\end{tabular}

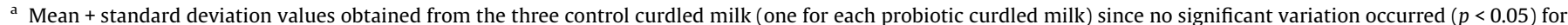
LA or oleic acid through ripening time. 

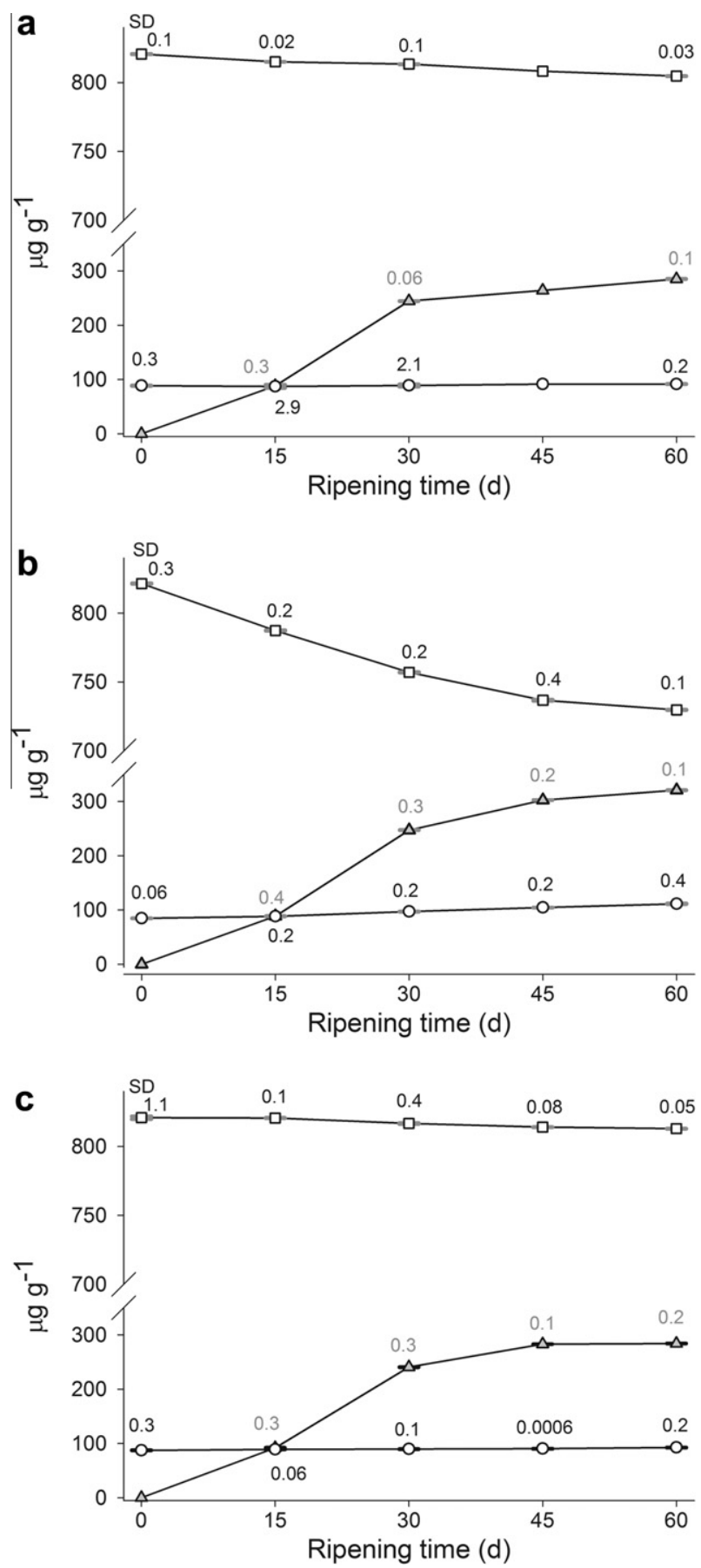

Fig. 3. Variation of concentrations of oleic acid $(\square)$, linoleic acid $(\bigcirc)$ or CLA $(\triangle)$ throughout ripening, in probiotic curdled milk inoculated with each probiotic strain: (a) B. lactis B94; (b) L. casei-01; (c) L. acidophilus La-5; SD - standard deviation.

In probiotic curdled milk inoculated with either $L$. casei-01, B. lactis B94 or L. acidophilus La-5 a statistical significant increase $(p<0.05)$ of CLA was observed reaching values from 284 to $321 \mu \mathrm{g} / \mathrm{g}$ of curdled milk at 60 days of ripening (Fig. 3). Microbial enzymes are known to be major contributors to CLA production since linoleic acid isomerase activity can convert LA to CLA, which is probably responsible for the significant differences in CLA content found between inoculated curdled milk and their control counterparts. According to Kishino, Ogawa, Yokozeki, \& Shimizu, 2009 and Ogawa, Matsumura, Kishino, Omura, \& Shimizu, 2001, the isomerization of LA in CLA by lactic acid bacteria results from two consecutive reactions: initially occurs hydration of LA forming 10-hydroxy-C18:1 which then undergoes isomerization by dehydration which is responsible to produce cis-9:trans-11, trans9:cis-11 or trans-9:trans-11 C18:2 isomers. The LA concentration increased $3-5 \%$ in B. lactis B94 $(p>0.05)$ or L. acidophilus La-5 $(p>0.05)$ curdled milk over ripening period; in probiotic curdled milk inoculated with $L$. casei-01, the increase of LA was of $29 \%$ $(p<0.05)$ after 60 days of ripening. The reported LA variations over ripening period could be related to lipolysis performed by each probiotic strain especially with $L$. casei-01; the increase of total free fatty acids was statistical significant in comparison to the corresponding control curdled milk (Rodrigues et al., 2011) being probably responsible for the increase of free fatty acids such as LA.

Studies on alternative substrates for the CLA production besides LA, have shown that these can be obtained from oleic acid (C18:1) with strains of $L$. delbruecki (Lin, 2006) reporting production of trans-8:trans-10, trans-10:cis-12 and cis9:trans-11 C18:2 isomers. This phenomenon could explain the significant decrease of oleic acid $(\mathrm{p}<0.05)$ in probiotic curdled milk inoculated with $L$ casei01. Slighter decreases were observed in those samples inoculated with B. lactis B94 and L. acidophillus La-5, respectively.

\section{Conclusions}

The production of CLA in new potential probiotic foods could indeed be considered as an added-value in functional foods since dietary CLA has been reported as important food additive with biological properties. Therefore, a single and reliable methodology based on optical fibre analysis could fasten the screening process for determining the potential of CLA production by probiotic bacteria in milk matrices. The optical fibre-based methodology showed performance and detection limits comparable to the GC-MS while avoiding the use of more expensive and sophisticated equipment.

\section{Acknowledgments}

This work has been developed under the scope of the FCT (Portugal) funded research projects PTDC/QUI/70970/2006 FCOMP-01-0124-FEDER-010896 (CATSENSOR) and PTDC/AGR-ALI/ 71051/2006 and FCOMP-01-0124-FEDER-008792 (PROBIOCAPS) and research grants SFRH/BD/48028/2008 and SFRH/BPD/65410/ 2009.

\section{References}

Adamczak, M., Bornscheuer, U. T., \& Bednarski, W. (2008). Properties and biotechnological methods to produce lipids containing conjugated linoleic acid. European Journal of Lipid Science and Technology, 110, 491-504.

Alonso, L., Cuesta, E. P., \& Gilliland, S. E. (2003). Production of free conjugated linoleic acid by L.Acidophilus and $L$. casei of human intestinal origin. Journal of Dairy Science, 86, 1941-1946.

Belury, M. A. (2002). Inhibition of Carcinogenesis by Conjugated Linoleic Acid: Potential Mechanisms of Action. The Journal of Nutrition, 132, 2995-2998.

Bhattacharya, A., Banu, J., Rahman, M., Causey, J., \& Fernandes, G. (2006). Biological effects of conjugated linoleic acids in health and disease. Journal of Nutritional Biochemistry, 17, 789-810.

Bisig, W., Eberhard, P., Collomb, M., \& Rehberger, B. (2007). Influence of processing on the fatty acid composition and the content of conjugated linoleic acid in organic and conventional dairy products - a review. Lait, 87, 1-19.

Coakley, M., Ross, R. P., Nordgreen, M., Fitzgerald, G., Devery, R., \& Stanton, C. (2003). Conjugated linoleic acid biosynthesis by human-derived Bifidobacterium species. Journal of Applied Microbiology, 94, 138-145.

Douglas, L. C., \& Sanders, M. E. (2008). Probiotics and prebiotics in dietetics practice. Journal of the American Dietetic Association, 108, 510-521.

FAO/WHO. Working Group Report on Drafting Guidelines for the Evaluation of Probiotics in Food. London, Ontario, Canada, April 30 and May 1, 2002. Available at: <http://www.who.int/foodsafety/fs_management/en/probiotic_guidelines.pdf>.

Fritsche, F., Rickert, R., Steinhart, H., Yurawecz, M. P., Mossoba, M. M., Sehat, N., et al. (1999). Conjugated linoleic acid (CLA) isomers: Formation, analysis, amounts in foods, and dietary intake. Lipid, 101, 272-276.

Kelley, N. S., Hubbard, N. E., \& Erickson, K. L. (2007). Conjugated Linoleic Acid Isomers and Cancer. The Journal of Nutrition, 137, 2599-2607. 
Kishino, S., Ogawa, J., Yokozeki, K., \& Shimizu, S. (2009). Microbial production of conjugated fatty acids. Lipid Technology, 21, 177-181.

Lin, T. Y. (2006). Conjugated linoleic acid production by cells and enzyme extract of Lactobacillus delbrueckii ssp Bulgaricus with additions of different fatty acids. Food Chemistry, 94, 437-441.

Lin, T. Y., Lin, C. W., \& Lee, C. H. (1999). Conjugated linoleic acid concentration as affected by lactic cultures and added linoleic acid. Food Chemistry, 67, 1-5.

Miller, J. N., \& Miller, J. C. (2005). Statistics and Chemometrics for Analytical Chemistry (5th ed.). New York: Pearson Prentice Hall.

Ogawa, J., Matsumura, K., Kishino, S., Omura, Y., \& Shimizu, S. (2001). Conjugated linoleic acid accumulation via 10-hidroxy-12-octadecaenoic acid during microaerobic transformation of linoleic acid by Lactobacillus acidophilus. Applied and Environmental Microbiology, 67, 1246-1252.

Oliveira, R. P. S., Perego, P., Converti, A., \& de Oliveira, M. N. (2009). Growth and acidification performance of probiotics in pure culture and co-culture with Streptococcus thermophilus: The effect of inulin. LWT - Food Science and Technology, 42, 1015-1021.

Ritzenthaler, K. L., McGuire, M. K., Falen, R., Shultz, T. D., Dasgupta, N., \& McGuire, M. A. (2001). Estimation of conjugated linoleic acid intake by written dietary assessment methodologies underestimates actual intake evaluated by food duplicate methodology. The Journal of Nutrition, 131, 1548-1554.

Rodrigues, D., Rocha-Santos, T. A. P., Pereira, C. I., Gomes, A. M., Malcata, F. X., \& Freitas, A. C. (2011). The potential effect of FOS and inulin upon probiotic bacterium performance in curdled milk matrices. LWT - Food Science and Technology, 44, 100-108.

Rodríguez-Alcalá, L. M., Braga, T. Malcata, F. X Gomes, A \& Fontecha, J. (2011) Quantitative and qualitative determination of CLA produced by Bifidobacterium and LAB by combining spectrophotometric and Ag+-HPLC techniques. Food Chemistry, 125, 1373-1378.

Sanders, M. E. (2003). Probiotics: Considerations for human health. Nutrition Reviews, 61, 91-99.

SigmaStat 3.0 (Statistic Software for Windows) 1994. Erkrath, Germany: Jandel Scientific.

Silva, L. I. B., M-Costa, A., Freitas, Ana. C., Rocha-Santos, T. A. P., \& Duarte, A. C. (2009). Polymeric nanofilm-coated optical fibre sensor for speciation of aromatic compounds. International Journal of Environmental Analytical Chemistry, 89, 183-197.

Silva, L. I. B., Rocha-Santos, T. A. P., \& Duarte, A. C. (2008a). Gas chromatographyoptical fibre (GC-OF) detector for speciation of aromatic hydrocarbons in confined areas. Analytical Sciences, 24, 963-966.

Silva, L. I. B., Rocha-Santos, T. A. P., \& Duarte, A. C. (2008b). Sensing of volatile organic compounds in indoor atmosphere and confined areas of industrial environments. Global NEST Journal, 10, 217-225.

Silva, L. I. B., Rocha-Santos, T. A. P., \& Duarte, A. C. (2008c). Development of fluorosiloxane polymer coated optical fibre sensor for detection of organic volatile compounds. Sensors and Actuators B, 132, 280-289.

Silva, L. I. B., Rocha-Santos, T. A. P., \& Duarte, A. C. (2008d). Comparison of a gas chromatography-optical fibre (GC-OF) detector with a gas chromatographyflame ionization detector (GC-FID) for determination of alcoholic compounds in industrial atmospheres. Talanta, 76, 395-399.
Silva, L. I. B., Rocha-Santos, T. A. P., \& Duarte, A. C. (2009). Remote optical fibre microsensor for monitoring BTEX in confined industrial atmospheres. Talanta, $78,548-552$

Wahle, K. W. J., Heys, S. D., \& Rotondo, D. (2004). Conjugated linoleic acids: Are they beneficial or detrimental to health? Progress in Lipid Research, 43, 553-587.

Lurdes Silva graduated in Chemistry and Environmental Sciences at the Instituto Superior de Estudos Interculturais e Transdisciplinares of the Instituto Piaget (Viseu, Portugal) in 2003 and obtained a Ph.D. in Chemistry in 2009 at the University of Aveiro (Portugal). She has worked at the Instituto Piaget as an Assistant Lecturer for 3 years and her research interests include the development of chemical sensors under a post-doctoral research grant awarded by Portuguese Foundation for Science and Technology (FCT, Portugal).

Dina Rodrigues graduated in Chemistry and Environmental Sciences at the Instituto Superior de Estudos Interculturais e Transdisciplinares of the Instituto Piaget (Viseu, Portugal) in 2007 and obtained a Master's Degree in Biomolecular Methods in 2009 at the University of Aveiro (Portugal). Her research interests are Analytical Chemistry, Environmental Science and Microbiology.

Ana C. Freitas graduated in Food Engineering in 1991 and obtained a Ph.D. in Science and Food Engineering in 1999 at the Portuguese Catholic University. She has been an Assistant Professor of Biotechnology at the Instituto Piaget (Portugal) since 1999 and her main research interests are Environmental and Food Sciences.

Ana M. Gomes graduated in Pharmacy (Pharmaceutical Industry) in 1990 and obtained a Ph.D. in Science and Food Engineering in 1999 at the Portuguese Catholic University. She has been an Assistant Professor of Biotechnology at the Portuguese Catholic University since 2006 and her main research interests are Functional Foods and Ingredients.

Teresa Rocha-Santos graduated in Analytical Chemistry in 1996 and obtained a Ph.D. in Chemistry in 2000 at the University of Aveiro (Portugal). She has been an Assistant Professor of Environmental Chemistry at the Instituto Piaget (Portugal) since 1999, an Associate Professor at the Instituto Piaget since 2009, and a postdoctoral researcher at University of Aveiro since 2010. Her main research interests are Analytical and Environmental Chemistry.

Maria Eduarda Pereira graduated in Ceramic and Glass Engineering at the University of Aveiro (Portugal) in 1984 and obtained a Ph.D. in Analytical Chemistry at University of Aveiro (Portugal) in 1997. She has been an Assistant Professor of Department of Chemistry at University of Aveiro (Portugal) since 1997 and her main research interests are Analytical and Environmental Chemistry.

Armando da Costa Duarte graduated in Chemical Engineering at the University of Oporto (Portugal) and obtained a Ph.D. in Public Health Engineering at University of Newcastle-upon-Tyne (England) in 1981. He has been a Professor of Chemistry at University of Aveiro (Portugal) since 1995 and his main research interests are Analytical and Environmental Chemistry. 